\title{
AIR QUALITY IN THE MAIN CITIES OF THE PEARL RIVER DELTA REGION
}

\author{
LOPES D. ${ }^{1, *}$ \\ HOI K.I ${ }^{1}$ \\ MOK K.M. ${ }^{1}$ \\ MIRANDA A.I. ${ }^{2}$ \\ YUEN K.V. ${ }^{1}$ \\ BORREGO C. ${ }^{2}$
}

\author{
${ }^{1}$ Department of Civil \& Environmental Engineering \\ Faculty of Science and Technology \\ University of Macau, Macau SAR, China \\ ${ }^{2}$ CESAM \& Department of Environment and Planning \\ University of Aveiro, Aveiro, Portugal Organization and Department
}

Received: 28/04/2016

Accepted: 28/06/2016

*to whom all correspondence should be addressed: e-mail: yb47403@umac.mo

\section{ABSTRACT}

In this study current status of the ambient air quality in the main cities of the Pearl River Delta region was investigated. Two special administrative regions (Macau and Hong Kong) and three major cities of Guangdong (Guangzhou, Dongguan and Foshan) were selected for analysis according to their geographical distribution, population, gross domestic product and industrial importance. The air quality of each city was diagnosed by using the monitoring data of 2014 and by applying the HYSPLIT model. The region is affected by transboundary pollution outside the delta area but the local emissions are the most important. The Asian Monsoon system also influences the air masses transport pattern.

Keywords: air quality status, backward trajectories, meteorology, Pearl river delta.

\section{Introduction}

The Pearl River Delta (PRD) is located in the southern coast of China and it is the second largest delta of the country. It has a geographical area of about $40,000 \mathrm{~km}^{2}$ comprised of nine municipalities of the Guangdong province and two special administrative regions (Macau and Hong Kong) (Figure 1) (The Government of the Hong Kong Special Administrative Region, 2005). According to the National Bureau of Statistics of China (2006) the gross domestic product of this region rose $33.2 \%$ from 2001 to 2006 . Its rapid development resulted in the increase of energy consumption, atmospheric emissions and the degradation of the ambient air quality. Since 2006 the PRD regional air quality monitoring network came into operation. The main objective of the network are: 1) provide accurate air quality data to help the decision makers to develop appropriate air pollution control measures; 2 ) evaluate the effectiveness of the air pollution control measures and 3) provide air quality information to the population. From 2006 to 2013, the annual averages for sulphur dioxide $\left(\mathrm{SO}_{2}\right)$, nitrogen oxides $\left(\mathrm{NO}_{2}\right)$ and particulate matter $\left(\mathrm{PM}_{10}\right)$ decreased by 62 ( 47 to $18 \mu \mathrm{g} \mathrm{m}^{-3}$ ), $13\left(46\right.$ to $40 \mu \mathrm{g} \mathrm{m}^{-3}$ ) and 15\% (74 to $63 \mathrm{\mu g} \mathrm{m}^{-3}$ ), respectively. For the same period, the ozone $\left(\mathrm{O}_{3}\right)$ increased by $13 \%\left(48\right.$ to $\left.54 \mathrm{\mu g} \mathrm{m}^{-3}\right)$. However, according to "Pearl River Delta Regional Air Quality Monitoring Network" report for 2013, the region continues to record several exceedances for $\mathrm{NO}_{2}, \mathrm{PM}_{10}$ and $\mathrm{O}_{3}$. To implement measures for air quality improvement in this region, it is necessary to study the current state of its pollution. The main objective of the present work is to investigate the current status of the ambient air pollution in the major cities of PRD chosen according to their geographical distribution, population, gross domestic product and industrial importance. Therefore, 
Macau, Hong Kong and three major cities of Guangdong (Guangzhou, Dongguan and Foshan) were investigated (Figure 1).

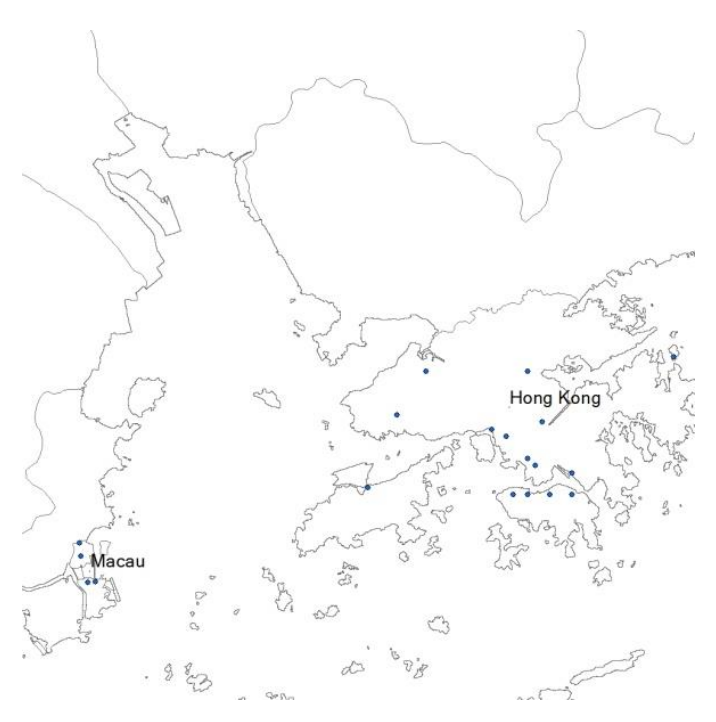

(a)

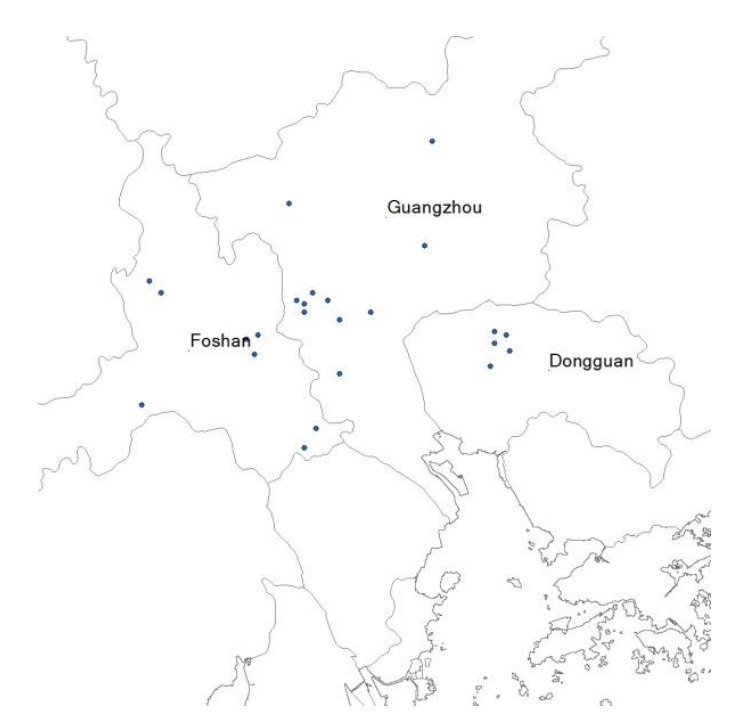

(b)

Figure 1. a) Location of the air quality monitoring stations of Macau and Hong Kong; b) location of the air quality monitoring stations in Guangzhou, Dongguan and Foshan

\section{Description of the main regions of Pearl River Delta}

In economic terms, Macau depends mainly on tourism and export business. Between 2000 and 2013, Macau recorded the highest gross domestic product growth of the world. (World Bank, 2014). The major anthropogenic sources are road traffic, industries, power plants and construction (DSPA, 2011). Macau is the second in the world with the highest road density (World Bank, 2014). Between 2000 and 2013, the number of vehicles increased about $50.0 \%$. Motorcycles are the vehicles most used. The main business sectors are manufacturing of pharmaceutical products, textile and garment (DSPA, 2011). Hong Kong is the region of PRD most developed in economics terms and the most modern (Louie et al., 2005). The main source of local emissions are road traffic and navigation (EPD, 2014). In addition the air quality in Hong Kong is strongly affected by heavy industrial activities (e.g. petrochemical manufacturing, power generation and steel) as well as from residential cooking/heating and agricultural burning in rural and urban areas of the PRD and south eastern of China (Kwok, Fung, Lau, \& Fu, 2010). Guangzhou is the capital of Guangdong province. It is the largest coastal city in the southern of China. With rapid urbanization and a steady increase of the population this region has transformed into a mega-urban center (Statistics Bureau of Guangzhou Municipality, 2014). In economic terms, Guangzhou depends mainly on industry, wholesale and retail trade, real estate and leasing and business services. The main source of emissions of air pollutants is road traffic (Zhang et al., 2014). In last decades, Dongguan has experienced rapid economic growth making it one of the most important industries centres of Guangdong province (Barletta et al., 2008). The main industries are furniture, shoe-making and electronic industries (Yuan et al., 2013). Foshan is one of the most populated and polluted areas of PRD and one of the largest industrial production areas of the world (Guangdong Provincial Environmental Monitoring Centre, 2013; Tan et al., 2012). The main industries are manufacture of home appliances and production of aluminium and stainless steel building materials with about 15.0 and $40.0 \%$ of the total production in China, respectively (Tan et al., 2011). 


\section{Approaches to analysis of data}

In this work the data from 43 air quality monitoring stations (11 in Guangzhou; 5 in Dongguan; 8 in Foshan; 4 in Macau; and 15 in Hong Kong) were analyzed for the year 2014 (Figure 1). The data of Macau and Hong Kong were obtained from the Macau Meteorological and Geophysical Bureau (SMG), and the Hong Kong Environmental Protection Bureau (HKEPD), respectively. For the other cities, the data were archived from the real-time air quality announcing platform of China. The air quality monitoring stations are classified into four types: 1) urban area that represents densely populated residential areas mixed with some commercial and/or industrial areas; 2 ) new town that represents mainly residential areas; 3 ) rural area; and 4) roadside that is a combination of residential/commercial area with heavy traffic and surrounded by many tall buildings (HKEPD, 2013). The monitored pollutants include respirable/fine particulate matter $\left(\mathrm{PM}_{10}\right.$ and $\mathrm{PM}_{2.5}$ ), nitrogen oxides ( $\mathrm{NO}_{x}$ including $\mathrm{NO}$ and $\left.\mathrm{NO}_{2}\right), \mathrm{O}_{3}$, carbon monoxide $(\mathrm{CO})$ and $\mathrm{SO}_{2}$. It is noted that the concentrations recorded by air quality monitoring stations are referenced with the National Ambient Air Quality Standards (NAAQS) of China (GB 3095-2012). To relate the air quality with the local meteorology, the meteorological data of these cities (wind, precipitation, temperature and sunshine) were also analyzed (Table 1).

Table 1. Meteorological information to the Pearl River Delta

\begin{tabular}{|c|c|c|c|c|c|c|c|c|c|c|c|c|}
\hline & Jan & Feb & Mar & Apr & May & Jun & Jul & Aug & Sep & Oct & Nov & Dec \\
\hline $\mathrm{T}\left({ }^{\circ} \mathrm{C}\right)$ & 14.7 & 14.0 & 17.6 & 21.9 & 25.2 & 27.9 & 28.7 & 27.8 & 27.7 & 24.9 & 21.1 & 14.2 \\
\hline Precipitation $(\mathrm{mm})$ & 3.2 & 45.0 & 210.4 & 186.8 & 575.2 & 339.8 & 251.3 & 296.7 & 129.4 & 56.1 & 40.1 & 43.2 \\
\hline Sunshine (h) & 8.2 & 4.8 & 4.5 & 4.8 & 4.1 & 5.1 & 7.0 & 7.3 & 6.8 & 7.4 & 5.4 & 5.5 \\
\hline Wind speed $\left(\mathrm{km} \mathrm{h}^{-1}\right)$ & 11.6 & 13.6 & 13.2 & 11.8 & 12.5 & 10.6 & 10.2 & 10.6 & 10.9 & 12.2 & 12.3 & 14.7 \\
\hline Wind direction $\left({ }^{\circ}\right)$ & $\mathrm{NE}$ & $\mathrm{NE}$ & $\mathrm{NE}$ & SE & SE & SE & SE & SE & SE & $\mathrm{NE}$ & $\mathrm{NE}$ & $\mathrm{NE}$ \\
\hline
\end{tabular}

The meteorological data adopted in this study were obtained from the National Climatic Data Center of NOAA, Macau SMG and HKEPD. Finally, the HYSPLIT model is employed to identify some plausible influence of local transport of emissions between these cities and the transboundary pollution outside the PRD according to the 48-hours backward trajectories of air masses.

\section{Results}

In this study $87.1 \%$ of air quality monitoring stations satisfies the minimum percentage $(75.0 \%$, according to the code of practice) (Macau Meteorological and Geophysical Bureau, 2015) of data collection efficiency. Since all the monitoring stations used in this study are located in residential, commercial, industrial and rural areas, the records are compared with Grade II limits of NAAQS. Table 2 shows the number of stations in each city that did not comply with the NAAQS for the six pollutants $\left(\mathrm{SO}_{2}, \mathrm{PM}_{10}\right.$, $\mathrm{PM}_{2.5}, \mathrm{NO}_{2}, \mathrm{O}_{3}$ and $\mathrm{CO}$ ) in the study period. The corresponding number of exceedances for the annual/daily/hourly limits for each pollutant is also shown.

The concentrations of $\mathrm{SO}_{2}$ and $\mathrm{CO}$ had the fewest counts of exceedances compared to other pollutants. For $\mathrm{SO}_{2}$, only Guangzhou and Dongguan recorded non-compliance with the daily limit $\left(150 \mu \mathrm{g} \mathrm{m}^{-3}\right)$ and hourly limit $\left(500 \mathrm{\mu g} \mathrm{m}^{-3}\right)$, respectively. Dongguan is the only city that recorded exceedances for $\mathrm{CO}$. Six, one and five air quality monitoring stations did not comply with the annual limit for $\mathrm{PM}_{10}\left(70 \mu \mathrm{g} \mathrm{m}^{-3}\right)$ in Guangzhou, Dongguan and Foshan, respectively. In Macau and Hong Kong all the monitoring stations complied with the annual limit for $\mathrm{PM}_{10}$; but there were $0-25(0-6.8 \%)$ exceedances of the daily limit $\left(150 \mu \mathrm{g} \mathrm{m}^{-3}\right)$ for $\mathrm{PM}_{10}$ in 2014. In Guangzhou, Dongguan and Foshan none of the air quality monitoring stations complied with the annual limit of $\mathrm{PM}_{2.5}$. In these cities the annual average was 1.3 times higher than the limit $\left(35 \mu \mathrm{g} \mathrm{m}^{-3}\right)$ for $\mathrm{PM}_{2.5}$. Three and one stations did not comply with annual limit for $\mathrm{PM}_{2.5}$ in Macau and Hong Kong, respectively. In addition, there were 1-62 (0.3-17\%) exceedances of the daily limit $\left(75 \mu \mathrm{g} \mathrm{m}^{-3}\right)$ for $\mathrm{PM}_{2.5}$. 
Table 2. Exceedances of national ambient air quality standards of China across main cities of PRD in 2014

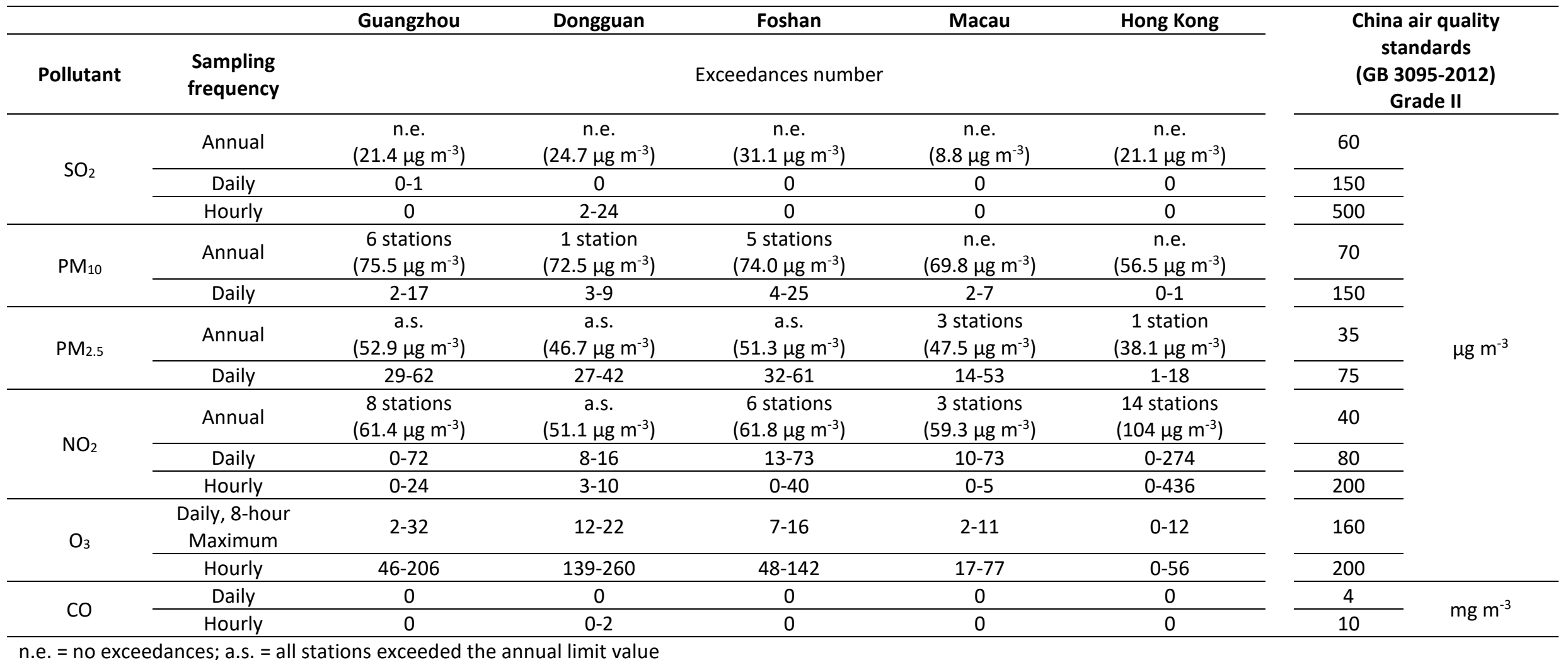

n.e. = no exceedances; a.s. $=$ all stations exceeded the annual limit value 
As for $\mathrm{NO}_{2}$, it has widespread violation of the annual/daily/hourly threshold values over the entire PRD. In Guangzhou, Dongguan, Foshan, Macau and Hong Kong about 73\%, 100\%, 75\%, 75\% and $93 \%$ of the air quality monitoring stations did not comply with the annual limit $\left(40 \mu \mathrm{g} \mathrm{m}^{-3}\right)$ for $\mathrm{NO}_{2}$, respectively. The air quality monitoring stations recorded 0-274 (0-75.1\%) exceedances of the daily $\mathrm{NO}_{2}$ limit $\left(80 \mathrm{\mu g} \mathrm{m}^{-3}\right)$. Finally, 0-436 (0-5.0\%) exceedances of the hourly limit $\left(200 \mathrm{\mu g} \mathrm{m}^{-3}\right)$ for $\mathrm{NO}_{2}$ were observed. For the pollutant $\mathrm{O}_{3}$, there were 0-32 (0-2.9\%) and 0-260 (0-3.0\%) exceedances of the daily maximum of the 8hour averaged limit $\left(160 \mu \mathrm{g} \mathrm{m}^{-3}\right)$ as well as the hourly limit $\left(200 \mu \mathrm{g} \mathrm{m}^{-3}\right)$, respectively. In Guangzhou, Dongguan, Foshan and Macau the highest concentrations of almost all pollutants shown in Table 2 were generally registered to north and northeast winds. Depending on the location of the air quality monitoring stations, the wind directions associated with the highest concentrations of Hong Kong could be northeast, east and southeast. This is due to the complex topography of Hong Kong (Fung, 2005) (Figure 2).

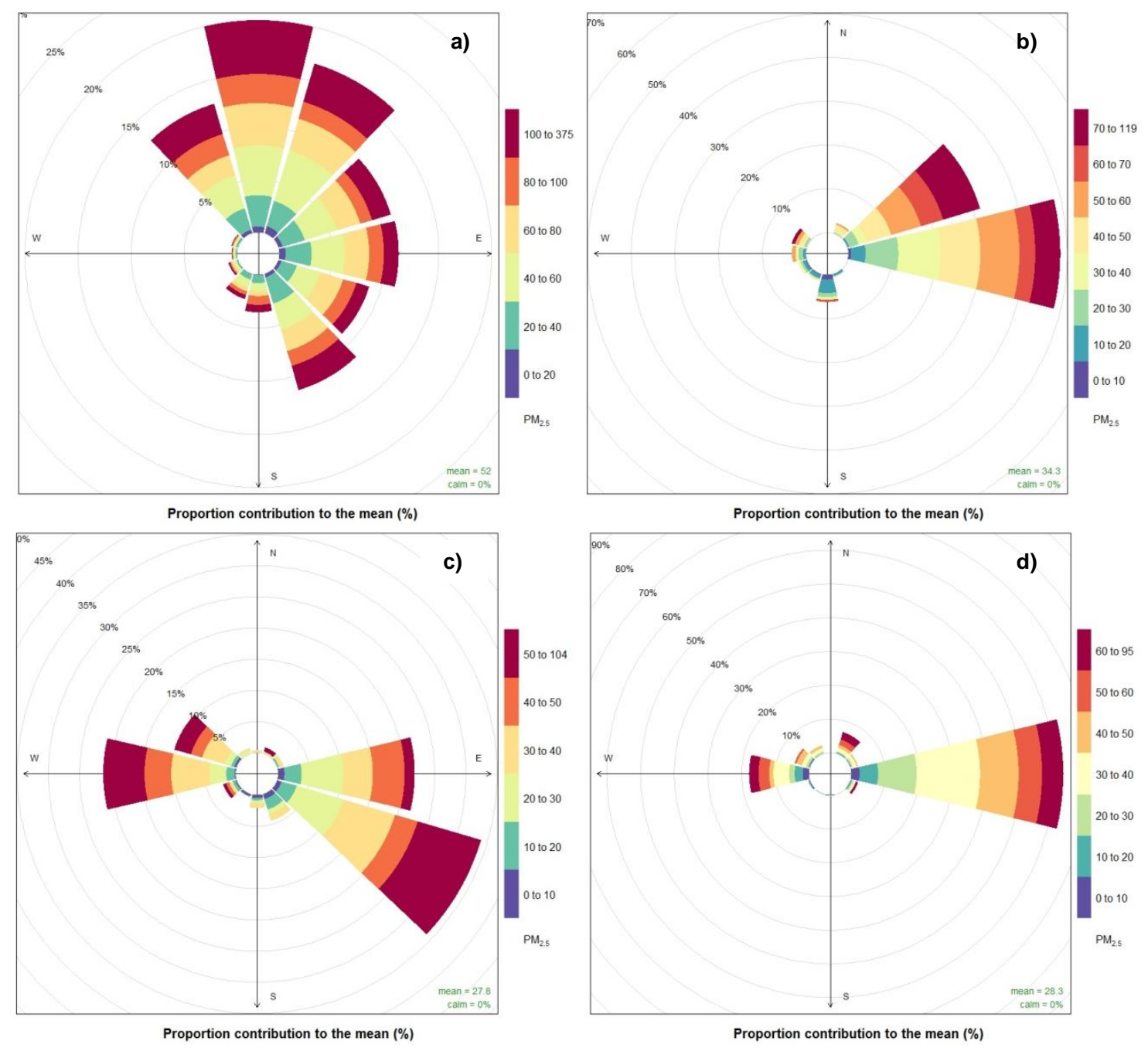

Figure 2. Concentration of $\mathrm{PM}_{2.5}$ (in $\mu \mathrm{g} \mathrm{m}^{-3}$ ) according with the wind directions to: a) Huadu Station (Guangzhou); b) Yuen Long station (Hong Kong); c) Tai Po station (Hong Kong); and d) Central Western station (Hong Kong) (Produced using package "openair")

Figure 3 shows the variation of the pollutant concentrations during the weekday, day and year for Huadu station, in Guangzhou. This station was selected for demonstration because the highest concentrations and the most count of exceedances were recorded here. In general the pollutants do not have relevant changes in concentrations throughout the week and day. For the case of ground-level ozone, the highest hourly concentrations are generally observed in the afternoon when the intensity of solar radiation is higher. In addition the highest monthly average concentration of ozone is in October. In autumn the 
prevailing winds are north and northeast. According to (DSEC, 2014) the autumn month with more hours of sunshine is October. So these records can be explained by the transboundary pollution outside the PRD and duration of sunshine. Except ozone which is formed through photochemical reactions, the highest concentrations of the other pollutants $\left(\mathrm{SO}_{2}, \mathrm{PM}_{10}, \mathrm{PM}_{2.5}, \mathrm{NO}_{2}\right.$ and $\left.\mathrm{CO}\right)$ in all cities were recorded in winter (i.e. November, December, January and February). This may be due to the smaller mixing height as well as the lower amount and frequency of rainfall during that period (Mok and Hoi, 2005) (Figure 3).
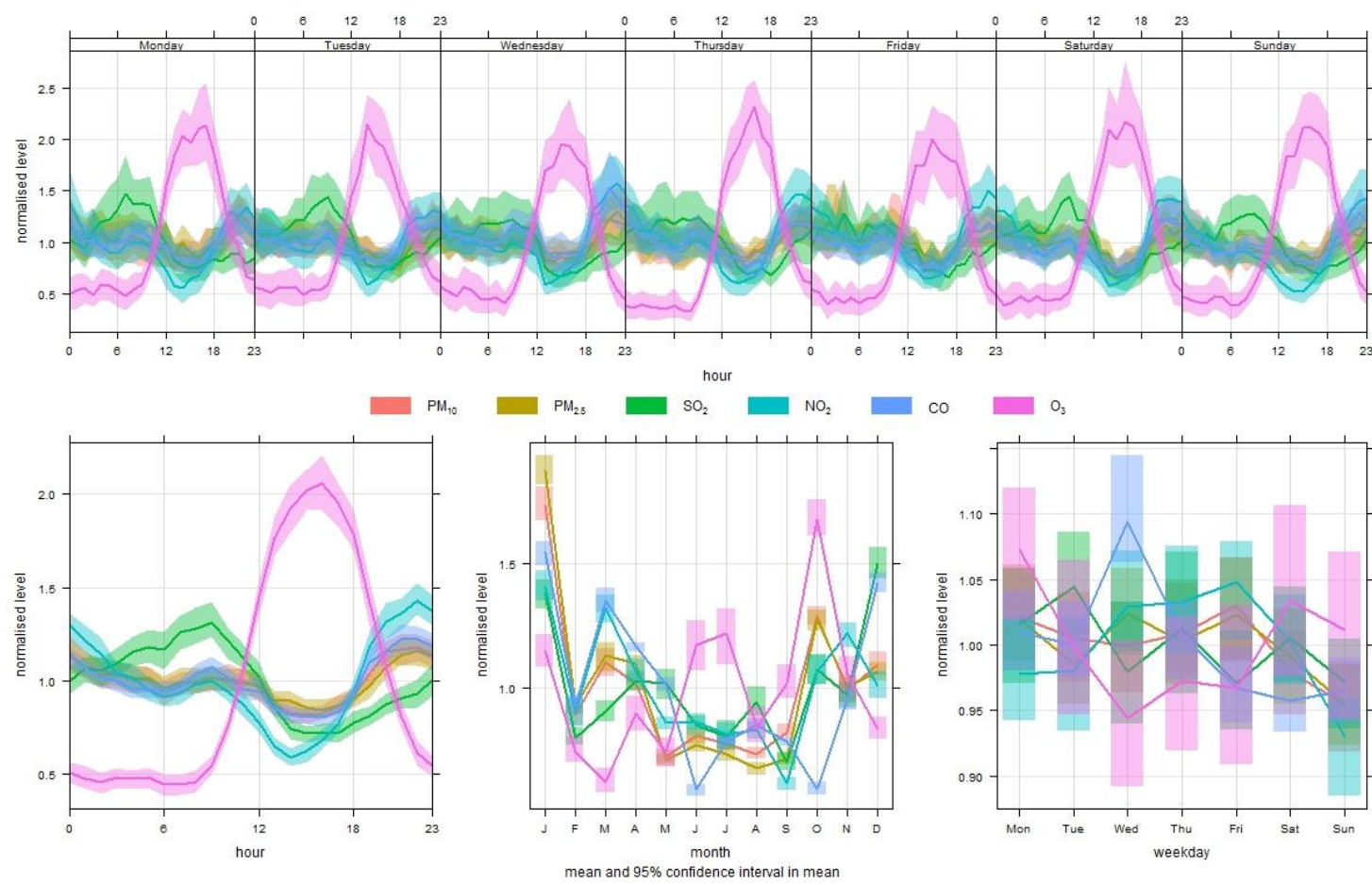

Figure 3. The variation of the pollutant concentrations during the weekday, day and year for Huadu station, in Guangzhou (latitude: 23.39 N, longitude: 113.21 E) (Produced using package "openair")

Finally, the HYSPLIT model is employed to identify some plausible influence of local transport of emissions between these cities and the transboundary pollution outside the PRD according to the 48-hours backward trajectories of air masses. The $\mathrm{PM}_{2.5}$, which is the dominant pollutant of PRD during the study period, is adopted for demonstration. Figure 4 shows the 48-hours backward trajectories of air masses tracking from Huadu (Guangzhou) and Central (Hong Kong) stations, for 2014. The Huadu and Central stations were selected for demonstration because the most and lowest count of exceedances were recorded here, respectively. For the Huadu station, in winter (i.e. November, December, January and February), Spring (March and April) and Autumn (October) the main air masses crossing the cities situated at the China-Taiwan strait region (i.e. cluster 1 and 4). In summer (i.e. May, June, July, August and September) this station was affected by air masses from the South China Sea (cluster 5 and 2). In annual terms the Huadu region was influenced by air masses from northeast (NE) (57.0\% of the year) and southwest (SW) (33.0\% of the year) (Figure $4-\mathrm{a} ; \mathrm{b}$ ). In addition, the highest and lowest $\mathrm{PM}_{2.5}$ mean concentrations were associated with the trajectories from northeast (cluster 1 and 4) and southeast (cluster 5), respectively (Figure 5 - a). For the Central station, in winter, Spring and Autumn the main air masses crossing the cities situated at the China-Taiwan strait region (i.e. cluster 1 and 3). In the summer this station was affected by air masses from the South China Sea (cluster 5 and 2). In annual terms the Central region was influenced by air masses from northeast (NE) (50.0\% of the year) and southwest (SW) (39.0\% of the year) (Figure $4-\mathrm{c}$; d). Finally, the highest and lowest $\mathrm{PM}_{2.5}$ mean concentrations were associated with the trajectories from northeast (cluster 1 and 3 ) and southeast (cluster 5), respectively (Figure 5 - b). 


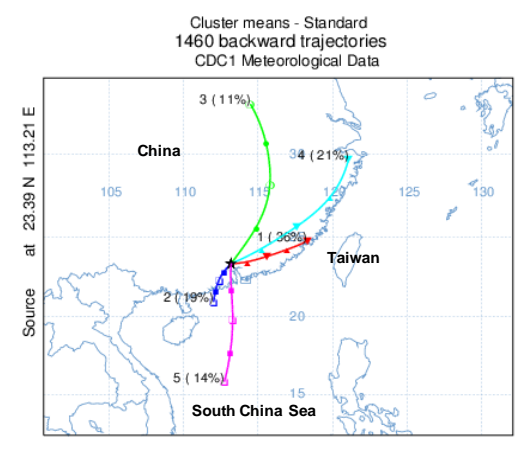

(a)

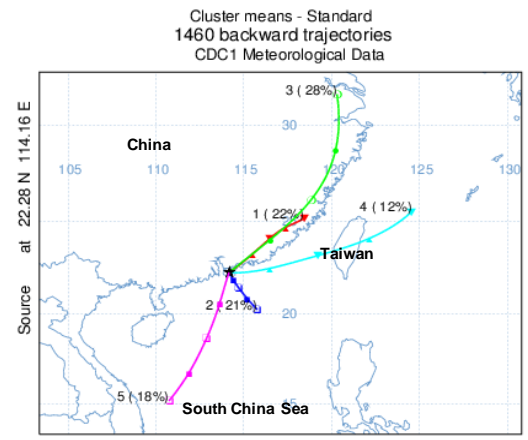

(c)

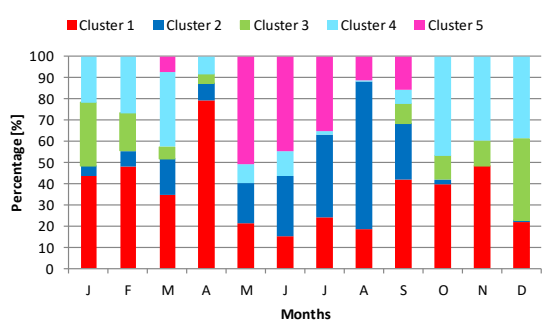

(b)

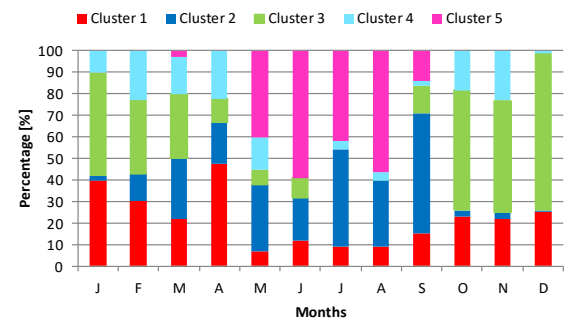

(d)

Figure 4. (a) 48 hours average backward trajectories for the 5 cluster at Huadu station, Guangzhou (latitude: $23.39 \mathrm{~N}$, longitude: $113.21 \mathrm{E}$ ), for 2014, with starting height at $250 \mathrm{~m}$ above sea level (percentages in parentheses reflect percentage of total 6 hours periods contributing to the average trajectory); (b) monthly distribution for Huadu station; (c) 48 hours average backward trajectories for the 5 cluster at Central station, Hong Kong (latitude: 22.28N, longitude: 114.16E), for 2014, with starting height at $250 \mathrm{~m}$ above sea level (percentages in parentheses reflect percentage of total 6 hours periods contributing to the average trajectory); and (d) monthly distribution for Central station (Produced using NOAA ARL Website: www.arl.noaa.gov)

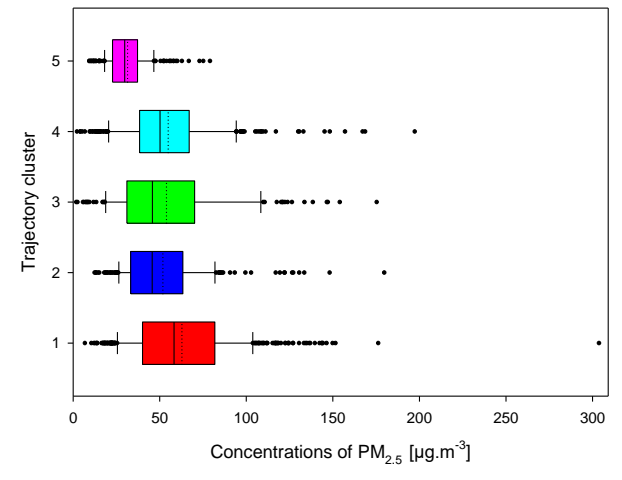

(a)

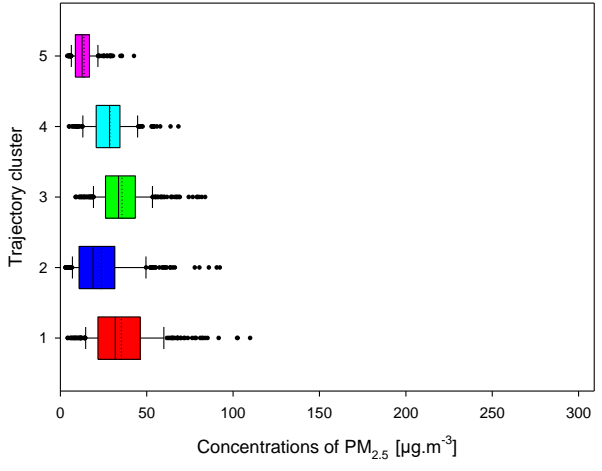

(b)

Figure 5. Concentration of $\mathrm{PM}_{2.5}$ in Huadu (a) and Central (b) stations, during 2014, according to trajectories clusters. Solid horizontal lines within each "box" represent the median and the dotted line is the mean. All the outliers are shown 


\section{Conclusions}

In 2014 PRD recorded severe exceedances of the national ambient air quality standards (GB 3095-2012) of China especially for $\mathrm{PM}_{2.5}$. It was concluded that $\mathrm{PM}_{2.5}$ is the dominant pollutant in this region. Furthermore, the highest concentrations were generally observed in winter and were associated with the northeast air mass trajectories crossing the China-Taiwan strait region. Therefore, the PRD region may be also affected by the transboundary pollution besides its own emissions.

\section{Acknowledgments}

This study is supported by the Science and Technology Development Fund of the Macau SAR government under grant no. 079/2013/A3, the university multi-year research grant MYRG2014-00038-FST of the research committee of University of Macau, and the university postgraduate studentship. The authors wish to thank the Macau Meteorological and Geophysical Bureau, Hong Kong Environmental Protection Department, and the real-time air quality announcing platform of China for supplying the data. The authors gratefully acknowledge the NOAA Air Resources Laboratory for the provision of the HYSPLIT transport and dispersion model and weather data used in this publication. Finally, the authors wish to thank the Openair project by provide the package "openair".

\section{References}

Barletta B., Meinardi S., Simpson I.J., Zou S., Sherwood Rowland F. and Blake D.R. (2008), Ambient mixing ratios of nonmethane hydrocarbons (NMHCS) in two major urban centers of the Pearl River Delta (PRD) region: Guangzhou and Dongguan, Atmospheric Environment, 42, 4393-4408. doi:10.1016/j.atmosenv.2008.01.028

DSEC (2014), Direç̧ão dos Serviços de Estatística e Censos (DSEC) [WWW Document]. URL http://www.dsec.gov.mo/ (accessed 9.24.14).

DSPA (Direç̧ão dos Serviços de Protecção Ambiental) (2011), Relatório do Estado do Ambiente em Macau. Macau.

Du Z., Mo J., Zhang Y. and Xu Q. (2014), Benzene, toluene and xylenes in newly renovated homes and associated health risk in Guangzhou, China, Building and Environment, 72, 75-81. doi:10.1016/j.buildenv.2013.10.013

EPD (2014), Environmental Protection Department (EPD) [WWW Document]. doi:http://www.epd.gov.hk/epd/

Fung J.C.H. (2005), Observational and modeling analysis of a severe air pollution episode in western Hong Kong, Journal of Geophysical Research, 110, D09105. doi:10.1029/2004JD005105

Guangdong Provincial Environmental Monitoring Centre (2013), Pearl River Delta Regional Air Quality Monitoring Network Purpose of the Report.

Hong Kong Environmental Protection Department (HKEPD) (2013), Air Quality in Hong Kong 2013, Hong Kong.

Huang W., Duan D., Zhang Y., Cheng H. and Ran Y. (2014), Heavy metals in particulate and colloidal matter from atmospheric deposition of urban Guangzhou, South China, Marine Pollution Bulletin, 85, 720-6. doi:10.1016/j.marpolbul.2013.12.041

Kwok R.H.F., Fung J.C.H., Lau A.K.H. and Fu J.S. (2010), Numerical study on seasonal variations of gaseous pollutants and particulate matters in Hong Kong and Pearl River Delta Region, Journal of Geophysical Research, 115, D16308. doi:10.1029/2009JD012809

Louie P., Watson J., Chow J., Chen A., Sin D. and Lau A. (2005), Seasonal characteristics and regional transport of PM in Hong Kong, Atmospheric Environment, 39, 1695-1710. doi:10.1016/j.atmosenv.2004.11.017

Macau (Meteorological and Geophysical Bureau) (2015), Annual Air Quality Reports.

Mok K.M. and Hoi K.I. (2005), Effects of meteorological conditions on $\mathrm{PM}_{10}$ concentrations - A study in Macau, Environmental Monitoring and Assessment, 102, 201-223. doi:10.1007/s10661-005-6022-6

National Bureau of Statistics of China (2006), China Statistical Yearbook [WWW Document]. URL http://www.stats.gov.cn/tjsj/ndsj/2013/indexee.htm (accessed 10.30.14).

Statistics Bureau of Guangzhou Municipality (2014). Statistical Yearbook 2013 [WWW Document]. URL http://www.gzstats.gov.cn/ (accessed 12.9.14).

Tan J., Guo S., Ma Y., He K., Yang F., Yu Y. and Wang J. (2011), Characteristics of atmospheric non-methane 
hydrocarbons in Foshan City, China, Environmental Monitoring and Assessment, 183, $297-305$. doi:10.1007/s10661-011-1922-0

Tan J.-H., Guo S.-J., Ma Y.-L., Yang F.-M., He K.-B., Yu Y.-C., Wang J.-W., Shi Z.-B. and Chen G.-C. (2012), Non-methane Hydrocarbons and Their Ozone Formation Potentials in Foshan, China, Aerosol and Air Quality Research, 387-398. doi:10.4209/aaqr.2011.08.0127

The Government of the Hong Kong Special Administrative Region (2005), The Greater Pearl River Delta.

World Bank (2014), The World Bank [WWW Document]. URL http://www.worldbank.org/ (accessed 9.5.14).

Yuan Z., Zhong L., Lau A.K.H., Yu J.Z. and Louie P.K.K. (2013), Volatile organic compounds in the Pearl River Delta: Identification of source regions and recommendations for emission-oriented monitoring strategies, Atmospheric Environment, 76, 162-172. doi:10.1016/j.atmosenv.2012.11.034

Zhang Z., Wang J., Chen L., Chen X., Sun G., Zhong N., Kan H. and Lu W. (2014), Impact of haze and air pollutionrelated hazards on hospital admissions in Guangzhou, China, Environmental Science and Pollution Research International, 21, 4236-44. doi:10.1007/s11356-013-2374-6 